\title{
Application of Self-retaining Bidirectional Barbed Absorbable Suture in Retroperito- neoscopic Partial Nephrectomy
}

Wang Ke, Zhang Yu-Lian, Lin Chun-Hua, Liu Dong-Fu, Men Chang-Ping, Wang Jian-Ming, Gao Zhen-Li

Department of Urology (WK, LCH, LDF, MCP, WJM, GZL) and Department of Gynecology (ZYL), Yantai Yuhuangding Hospital, Yantai 264000, China

\section{ABSTRACT}

Objective: To investigate the safety and feasibility of self-retaining bidirectional barbed absorbable suture application in retroperitoneoscopic partial nephrectomy.

Materials and Methods: From Sep 2011 and Aug 2012, 76 cases of retroperitoneoscopic partial nephrectomy were performed at our hospital. The patients were divided into two groups: self-retaining barbed suture (SRBS) group $(\mathrm{n}=36)$ and non-SRBS group $(\mathrm{n}=$ 40). There was no significant difference in age, sex, tumor size and location between the two groups. Clinical data and outcomes were analyzed retrospectively.

Results: All 76 cases of retroperitoneoscopic partial nephrectomy were successfully performed, without conversion to open surgery or serious intraoperative complications. In the SRBS group, the suture time, warm ischemia time and operation blood loss were significantly shorter than that of non-SRBS group $(p<0.01)$, and operation time and hospital stay were shorter than that of non-SRBS group $(\mathrm{p}<0.05)$.

Conclusions: The application of self-retaining bidirectional barbed absorbable suture in retroperitoneoscopic partial nephrectomy could shorten suture time and warm ischemia time, with good safety and feasibility, worthy of being used in clinic.

\section{ARTICLE INFO}

Key words:

Nephrectomy; Carcinoma,

Renal Cell

Int Braz J Urol. 2014; 40: 220-4

Submitted for publication:

February 01, 2013

Accepted after revision:

July 25, 2013

\section{INTRODUCTION}

With the fast development of laparoscopic technique, laparoscopic partial nephrectomy (LPN) became a new way to treat T1 renal cell carcinoma (RCC) (1). Compared with open partial nephrectomy (OPN), LPN has many advances such as less postoperative pain therapy, shorter hospital stay time and quicker recovery (2-4). But it has an increased complication rate and longer warm ischemia time $(5,6)$. Quill SRS bidirectional barbed suture (Quill Self-Retaining System; Angiotech Pharmaceuticals, Vancouver, British Columbia, Canada) consists of a delayed-absorbable material (polydioxanone) cut with barbs that prevents slippage through tissue and avoids to knot, increases efficiency, and shortens suture time. Quill SRS has been described for use in LPN and can decrease suture time and warm ischemia time (WIT). From September 2011 to August 2012, 76 cases of retroperitoneoscopic partial nephrectomy (RPN) were performed at our hospital, and Quill SRS was used in 36 cases of them. Clinical data and outcomes were analyzed retrospectively.

\section{MATERIALS AND METHODS}

A total of 76 patient records were reviewed; all patients were diagnosed with renal carcinoma by CT or MRI before operation, all patients were randomly divided into two groups: self- retaining barbed suture (SRBS) group ( $\mathrm{n}=$ 
36) and non-SRBS ( $\mathrm{n}=40)$ group. There were no significant differences in age, sex, tumor size and location between the two groups (Table-1). All cases were in stage $\mathrm{T}_{1} \mathrm{~N}_{0} \mathrm{M}_{0}$ according to AJCC. Prior to the study, the protocol was approved by our local institutional ethics committee, and in accordance to the ethical guidelines of the $1975 \mathrm{Hel}-$ sinki Declaration. Written, informed consent was obtained from all of the subjects.

\section{Retroperitoneoscopic Partial Nephrec- tomy Procedure (left)}

The patient was placed in the right lateral position. Port A (posterior axillar line under the 12th rib) was created using a home-made balloon and $500-800 \mathrm{~mL}$ of $\mathrm{CO}_{2}$ was inflated. Port $\mathrm{B}$ (anterior axillar line under the 11st rib) was created and digitally guided. Port C (median axillar line, $1-2 \mathrm{~cm}$ above the iliac crest) was created and a $10 \mathrm{~mm}$ trocar was inserted. A $12 \mathrm{~mm}$ trocar was inserted in port A. Initially the lumbar fascia was sutured and next the skin and muscle were sutured. After the access of the peritoneal cavity the extraperitoneal and perirrenal fascias were separated using an ultrasonic scissor from up to down and from anterior to posterior location, and the peritoneal reflection and the Gerota fascia were clearly identified. Gerota fascia was dissected close to the peritoneal reflection, beyond the renal superior pole and $3-4 \mathrm{~cm}$ below the inferior kidney pole. At this site, the dissection must be careful in order to identify the ureter. The renal pedicle was dissected and a bulldog clamp was used to clamp the renal artery. The mass was excised using a laparoscopic scissor maintaining a $0.5-1.0 \mathrm{~cm}$ margin. For SRBS group, a single barbed bidirectional suture 1-PDO $14 \times 14 \mathrm{~cm} \mathrm{1/2}$ was used to suture the kidney (Figure-1). One needle entered first through kidney surface and stopped at the middle of the whole suture. Continuous suture was used to close renal pelvis or calices; then the needle went out through contralateral surface of the kidney,

Table 1 - Comparisons between characteristics of operation and postoperative outcomes.

\begin{tabular}{|c|c|c|c|}
\hline Variable & $\begin{array}{l}\text { SRBS group } \\
\quad(n=36)\end{array}$ & $\begin{array}{c}\text { Non-SRBS } \\
\text { group }(n=40)\end{array}$ & P Value \\
\hline $\operatorname{Age}(y)$ & $51.3 \pm 10.1$ & $50.8 \pm 11.2$ & $>0.05$ \\
\hline $\operatorname{Sex}(m / f)$ & $21 / 15$ & $24 / 16$ & $>0.05$ \\
\hline \multicolumn{4}{|l|}{ Tumor } \\
\hline Size $(X \pm s) \mathrm{cm}$ & $3.1 \pm 1.2$ & $3.0 \pm 1.4$ & $>0.05$ \\
\hline Left/right(n) & $16 / 20$ & $17 / 23$ & $>0.05$ \\
\hline Location (upper pole/middle part/ lower pole) (n) & $14 / 5 / 17$ & $17 / 4 / 19$ & $>0.05$ \\
\hline Suture time $(X \pm S)$ min & $10.4 \pm 3.2$ & $19.4 \pm 6.7$ & $<0.01$ \\
\hline Warm ischemia time $(X \pm s)$ min & $15.2 \pm 4.2$ & $24.1 \pm 5.6$ & $<0.01$ \\
\hline Operation time $(X \pm s) \min$ & $78.5 \pm 15.4$ & $90.3 \pm 18.1$ & $<0.05$ \\
\hline Blood loss $(X \pm s) m L$ & $60.5 \pm 21.2$ & $110.4 \pm 21.1$ & $<0.01$ \\
\hline Blood transfusion(n) & 0 & 2 & $>0.05$ \\
\hline Urine leak (n) & 0 & 1 & $>0.05$ \\
\hline Blood urine(n) & 1 & 4 & $>0.05$ \\
\hline Hospital stay $(X \pm S)(d)$ & $5.9 \pm 2.1$ & $6.8 \pm 2.3$ & $>0.05$ \\
\hline
\end{tabular}


Figure 1 - a) Bi-directional barbed suture (Quill SRS); b) Barbs that change direction at the mid-point of the doublearmed suture.

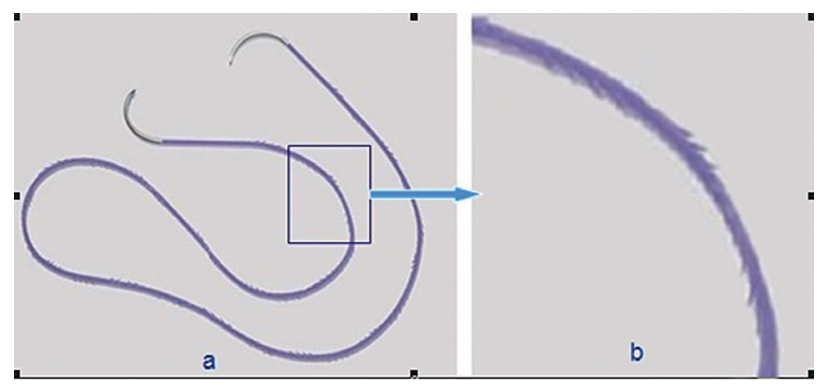

and continuous suture was used again to close the kidney. Another needle was used to close the left part. After the suture, the left quill line was used to tie a knot, or a Hem-o-lock was used to close at the end of suture (Figure-2).

For the non-SRBS group, the tumor bed and the collecting system were sutured with a continuous 3-0 polyglactin suture then superficial renorrhaphy was performed with running 3-0 polyglactin line intermittently, with Hem-o-lock clip for every suture. The bulldog clamp was removed and there was no bleeding in the surgical field and the tumor was removed through the Port A.

\section{Statistical analysis}

Statistical analyses were performed with SPSS software for Windows (Statistical Product and Service Solutions, version 10.0, SSPS Inc, Chicago, IL, USA). Categorical variables were compared with

Figure 2 - Hem-0-lock close at the end of suture.

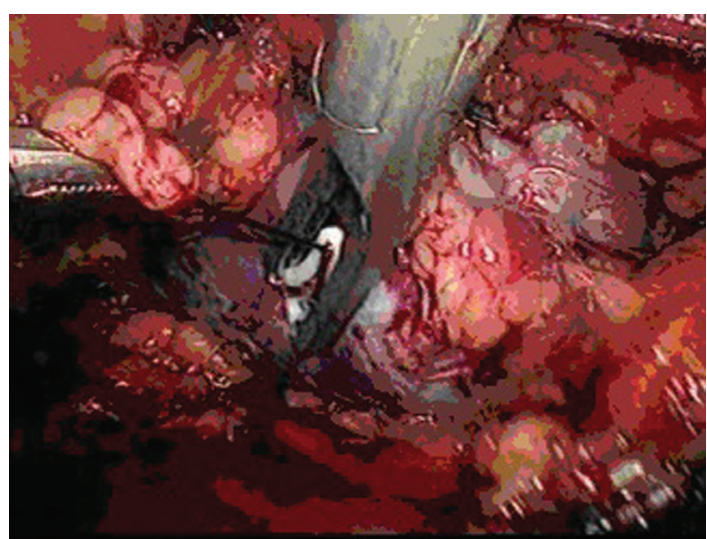

the chi-square test; continuous variables were compared with the Mann-Whitney U test. A value for $\mathrm{P}$ $<0.05$ was considered statistically significant.

\section{RESULTS}

All 76 cases of retroperitoneoscopic partial nephrectomies were successfully performed, without conversion to open surgery or important intraoperative complications. All patients were followed for 1 11 months, without local recurrence and distant metastasis. In the SRBS group, the suture time, warm ischemia time and operation blood loss were shorter than that of non-SRBS group significantly; operation time and hospital stay were also shorter than that of non-SRBS group (Table-1).

\section{DISCUSSION}

With the widespread application of B ultrasound, CT and MRI exams, incidental renal cell carcinoma increased generally recently, which has characteristics of small size, low stage, slow growth and low potential for metastasis, with better prognosis than symptomatic renal cell carcinoma; the operation is the gold standard treatment for most T1 RCC currently (7).

Partial nephrectomy (PN) has been a new treatment for T1a renal cell carcinoma(RCC). Some studies show that chronic kidney disease (CKD) has relations with cardiovascular diseases (8), and when GFR $<60 \mathrm{~mL} / \mathrm{min}$, the risks of death and in hospital treatment increase (9). RN is considered as a risk factor for the genesis and the development of CKD; PN treatment keeps more kidney units left and decreases those affectted $(10,11)$. RN is a risk factor for the genesis and worsening of CKD; the studies showed that RN could increase the death rate and renal failure of RCC patients $(12,13)$, PN can get the same outcomes with RN in histology, and it can maintain the kidney and cardiovascular function better in a long term follow-up $(11,14)$.

PN includes open partial nephrectomy (OPN), laparoscopic partial nephrectomy (LPN), and robot-assisted partial nephrectomy (RAPN). LPN has gained increased acceptance with equivalent results at oncological and renal function 
outcomes as OPN, with many advances such as less postoperative pain therapy, shorter hospital stay, and quick recovery (2-4).

LPN includes transperitoneal approach and retroperitoneoscopic approaches. Gill described the first retroperitoneoscopic partial nephrectomy in 1994 (15), Winfield finished the first retroperitoneoscopic partial nephrectomy in 1993 (16). The retroperitoneoscopic approach has advantages of easier controlling of kidney vessel, less disturbance of internal organs, and disadvantages of smaller operation field, less anatomic landmarks. Anatomic, programmed and standard operation could make up the disadvantages of the retroperitoneoscopic approach (1).

Even though with more advantages, LPN keeps some challenge for many urologists, resulting in more intraoperative complications (blood and urine leak etc.) and longer WIT. The WIT is closely related with kidney function, while the WIT > 30 minutes, the kidney function was affected more than 3-5 times $(17,18)$. Suturing was the best way to keep kidney and to avoid urine leak, but it had great challenges $(19,20)$. The good suturing techniques could decrease the rate of complications and shorten suturing time (3). Hem-o-lok substitution for knots was valid and safe $(20,21)$, and could shorten suturing time and reduce WIT, but renal closures was still not tighter enough.

Bidirectional barbed sutures are manufactured from monofilament fibers via a micromachining technique that cuts barbs into the suture around the circumference in a helical pattern. The barbs are separated from one another by a distance of 0.88 to $0.98 \mathrm{~mm}$ and are divided into 2 groups that face each other in opposing directions from the suture midpoint. The use of knotless, barbed suture can securely suture tissues with less time, to close multiple layers tissues at the same time, and to decrease operation blood loss (22). Our study showed that Quill SRS barbed suture could improve efficiency in LPN, simplifying the suturing procedure, shortening suture time and WIT, decreasing blood loss, with a tighten renal closure, and decrease of the incidence of urine leaks, hemorrhage, or other complications. Quill SRS consists of a delayed-absorbable material (polydioxanone) cut with barbs, which could pre- vent slippage through tissue and strengthen the suture, decreasing the chance of blood loss.

The application of Quill SRS bidirectional barbed absorbable suture in retroperitoneoscopic partial nephrectomy could shorten suturing time and warm ischemia time, with good safety and feasibility, worthy of being used generally in clinic.

\section{CONFLICT OF INTEREST}

None declared.

\section{REFERENCES}

1. Xie M, Wang K, Men CP: Anatomic and programmed retroperitoneal laparoscopic partial nephrectomy( with 125 cases of reports). Chinese Journal of Endourology. Electronic Version. 2012: 6: 11-4.

2. Gill IS, Matin SF, Desai MM, Kaouk JH, Steinberg A, Mascha $\mathrm{E}$, et al.: Comparative analysis of laparoscopic versus open partial nephrectomy for renal tumors in 200 patients. J Urol. 2003; 170: 64-8.

3. Gill IS, Kavoussi LR, Lane BR, Blute ML, Babineau D, Colombo JR Jr, et al.: Comparison of 1,800 laparoscopic and open partial nephrectomies for single renal tumors. J Urol. 2007; 178: 41-6.

4. Gong EM, Orvieto MA, Zorn KC, Lucioni A, Steinberg GD, Shalhav AL: Comparison of laparoscopic and open partial nephrectomy in clinical T1a renal tumors. J Endourol. 2008; 22: 953-7.

5. Kane CJ, Mallin K, Ritchey J, Cooperberg MR, Carroll PR: Renal cell cancer stage migration: analysis of he National Cancer Data Base. Cancer. 2008; 113: 78-83.

6. Collins S, McKiernan J, Landman J: Update on the epidemiology and biology of renal cortical neoplasms. J Endourol. 2006; 20: 975-85.

7. Ljungberg B, Cowan NC, Hanbury DC, Hora M, Kuczyk MA, Merseburger AS, et al.: EAU guidelines on renal cell carcinoma: the 2010 update. Eur Urol. 2010; 58: 398-406.

8. Go AS, Chertow GM, Fan D, McCulloch CE, Hsu CY: Chronic kidney disease and the risks of death, cardiovascular events, and hospitalization. N Engl J Med. 2004; 351: 1296-305. Erratum in: N Engl J Med. 2008; 18: 4.

9. Shlipak MG, Fried LF, Cushman M, Manolio TA, Peterson D, Stehman-Breen $\mathrm{C}$, et al.: Cardiovascular mortality risk in chronic kidney disease: comparison of traditional and novel risk factors. JAMA. 2005; 293: 1737-45. 
10. Medina-Polo J, Romero-Otero J, Rodríguez-Antolín A, Domínguez-Esteban M, Passas-Martínez J, Villacampa-Aubá F, et al.: Can partial nephrectomy preserve renal function and modify survival in comparison with radical nephrectomy? Scand J Urol Nephrol. 2011; 45: 143-50.

11. Russo P, Huang W: The medical and oncological rationale for partial nephrectomy for the treatment of T1 renal cortical tumors. Urol Clin North Am. 2008; 35: 635-43.

12. Thompson RH, Boorjian SA, Lohse CM, Leibovich BC, Kwon ED, Cheville JC, et al.: Radical nephrectomy for pT1a renal masses may be associated with decreased overall survival compared with partialnephrectomy. J Urol. 2008; 179: 46871; discussion 472-3.

13. Huang WC, Levey AS, Serio AM, Snyder M, Vickers AJ, Raj GV, et al.: Chronic kidney disease after nephrectomy in patients with renal cortical tumours: a retrospective cohort study. Lancet Oncol. 2006; 7: 735-40.

14. Crépel M, Jeldres C, Perrotte P, Capitanio U, Isbarn H, Shariat SF, et al.: Nephron-sparing surgery is equally effective to radical nephrectomy for T1BNOM0 renal cell carcinoma: a population-basedassessment. Urology. 2010; 75: 271-5.

15. Gill IS, Delworth MG, Munch LC: Laparoscopic retroperitoneal partial nephrectomy. J Urol. 1994; 152: 1539-42.

16. Winfield HN, Donovan JF, Godet AS, Clayman RV: Laparoscopic partial nephrectomy: initial case report for benign disease. J Endourol. 1993; 7: 521-6.

17. Becker F, Van Poppel H, Hakenberg OW, Stief C, Gill I, Guazzoni G, Montorsi F, et al.: Assessing the impact of ischaemia time during partial nephrectomy. Eur Urol. 2009; 56: 625-34.
18. Yossepowitch 0, Eggener SE, Serio A, Huang WC, Snyder ME, Vickers AJ, et al.: Temporary renal ischemia during nephron sparing surgery is associated with short-term but not long-term impairment in renalfunction. J Urol. 2006; 176: 1339-43; discussion 1343.

19. Sammon J, Petros F, Sukumar S, Bhandari A, Kaul S, Menon $M$, et al.: Barbed suture for renorrhaphy during robotassisted partial nephrectomy. J Endourol. 2011; 25: 529-33.

20. Orvieto MA, Chien GW, Laven B, Rapp DE, Sokoloff MH, Shalhav AL: Eliminating knot tying during warm ischemia time for laparoscopic partial nephrectomy. J Urol. 2004; 172: 2292-5.

21. Benway BM, Cabello JM, Figenshau RS, Bhayani SB: Slidingclip renorrhaphy provides superior closing tension during robot-assisted partial nephrectomy. J Endourol. 2010; 24: 605-8.

22. Gözen AS, Arslan M, Schulze M, Rassweiler J: Comparison of laparoscopic closure of the bladder with barbed polyglyconate versus polyglactin suture material in the pigbladder model: an experimental in vitro study. J Endourol. 2012; 26: 732-6.

\footnotetext{
Correspondence address: Zhang Yu-lian, MD Department of Gynecology Yantai Yuhuangding Hospital, Yantai 264000, China E-mail: zhyl0914@sina.com
} 